\title{
STRATIGRAPHIC NOISE IN TIME SERIES DERIVED FROM ICE CORES
}

\author{
by
}

David A. Fisher,

\begin{abstract}
(Polar Continental Shelf Project, Energy, Mines and Resources, 880 Wellington St., Ottawa,
\end{abstract} Ontario K1A 0E4, Canada)

Niels Reeh and H.B. Clausen

(Geophysical Isotope Laboratory, University of Copenhagen, Haraldsgade 6, DK-2200 Copenhagen, Denmark)

\begin{abstract}
Because of snow drifting, two time series of any variable derived from two adjacent ice cores will differ considerably. The size and statistical nature of this noise element is discussed for two kinds of measured substance. A theory is developed and compared to data from Greenland and Canadian Arctic ice cores. In case 1 , the measured substance can diffuse and the seasonal cycle degrade with time and depth, e.g. $8\left({ }^{18} \mathrm{O}\right)$. In case 2 , the measured substance cannot diffuse, e.g. microparticles. The case 2 time series contain drift noise proportional to that in the accumulation series. For accumulation series, the spectral power is concentrated at the high frequencies, i.e. is "blue". Such noise can be easily reduced by taking relatively short time averages. The noise in the case 1 time series, however, starts out "blue" but quickly diffuses to have a "red" character with significant power at longer wavelengths, and many decades of such series must be averaged to reduce the noise level. Because the seasonal amplitude of any given variable is an important input to the drift noise and because the seasonal amplitudes of some variable types are latitude-dependent, some sites have inherently less drift noise than others.
\end{abstract}

\section{INTRODUCTION}

Ice cores from cold high-latitude sites have been dated and analyzed to yield time series of a multitude of atmosphere-related variables. For interpretation of these palaeoclimatic series it is necessary to know how much signal is present, how much noise and the source of noise. Since power spectra of these ice-core-derived series have been extensively used to search for natural periodicities, it is important to know the noise spectra and the physical effects that might alter the signal and/or noise spectra.

Chemical constituents, microparticles and the stable isotope content $\delta\left({ }^{18} \mathrm{O}\right)$ have annual cycles. They are deposited in the snow and are thus weighted by the seasonal accumulation cycle. Since the snow surface is irregular and changes from storm to storm, a time series based on a given core contains a random element caused by the surface irregularities; we call this local noise. Furthermore, some of the constituents themselves can be transported by diffusion within the snow and firn altering the nature of the local noise (and signal) in the resulting series.

We examine here the local noise in the accumulation series $\lambda$. Impurities that do not diffuse contain local noise of the same amount and character as the $\lambda$ local noise. We also examine the local noise in $\delta\left({ }^{18} \mathrm{O}\right)^{*}$ series as an example of a constituent that diffuses in the snow and firn.

* $\delta\left({ }^{18} \mathrm{O}\right)$ is a measure of the ${ }^{18} \mathrm{O} /{ }^{16} \mathrm{O}$ ratio in the snow and is given in parts per thousand $(\% \circ$ ) (Dansgaard and others 1973).
We emphasize that the term "noise" is used here to describe the uncorrelated part of two or more $\lambda$ or $\delta$ time series obtained from sites within a few kilometres of each other and around which the surface is not complicated by extreme local topography and, furthermore, where the snow is not greatly reworked after its fall. Thus, one would not expect the analysis to apply to large parts of Antarctica where $\lambda$ is small and the accumulation is reworked considerably during each storm. Also since the noise investigated here is of a local character the analysis tells us how reproducible the $\lambda$ and $\delta$ time series of a given site are and how the statistical nature of the local noise arises. The larger question of extracting the climatic signal and noise parts of these series is not addressed in this paper.

\section{FIRN AND CORE RECORDS}

2.1. Devon Island records

In 1972 and 1973 two bore holes were drilled 27 $m$ apart on the Devon Island ice cap (Table I). Both holes are about $900 \mathrm{~m}$ from the summit ridge and 7.5 $\mathrm{km}$ west of the highest surface elevation of the ice cap. Seasonal $\delta\left({ }^{18} \mathrm{O}\right)$ oscillations die out after only 14 cycles due to diffusion in the firn.

The $\delta\left({ }^{18} \mathrm{O}\right)$ samples were cut initially according to a theoretical time scale. The final time scale used to convert depths to ages is based on measurements of annual layer thickness and vertical velocity, and is substantiated by cross-comparison with the Camp Century core. This time scale, which has been discussed in Fisher (unpublished, 1979), Koerner (1977), and Paterson and others (1977) is accurate to better than $\pm 10 \%$ in the interval between $5300 \mathrm{BP}$ and the present.

2.2. GISP records

During the Greenland Ice Sheet Program (GISP) groups of closely-spaced shallow firn and ice cores, i.e. cores with depths of up to a few hundreds of metres, were recovered at six sites on the Greenland ice sheet (Table I). The records were dated absolutely using several methods (Dansgaard and others 1973, Hammer 1977, Hammer and others 1978). The absolute dating is accurate within 1 or 2 a. Relative dating errors between adjacent records, which would seriously affect the study of the noise, are considered very unlikely.

\section{SIGNALS AND NOISE}

The separation of the signal and noise parts of annual layer thickness $\lambda$ or $\delta$ time series is performed in the following way. Consider a number $m \geqslant 2$ of time series all covering the same time span of $M$ a. The first step is to perform a two-way analysis of variance, separating the variances ascribable to temporal variability, regional areal variability and local areal variability (Weatherburn 1968: 214). If the mean values of $\lambda$ or $\delta$ for two stations are significantly different the residuals from the mean values are used in the variance calculations. 
TABLE 1. DRILL SITES

\begin{tabular}{|c|c|c|c|c|c|c|c|c|}
\hline Site & $\begin{array}{l}\text { Position } \\
\text { Lat(N) }\end{array}$ & Long(W) & $\begin{array}{l}\text { Elevation } \\
\text { (m) }\end{array}$ & $\begin{array}{l}\text { 10-metre } \\
\text { temperature } \\
\left({ }^{\circ} \mathrm{C}\right)\end{array}$ & $\begin{array}{l}\text { Mean } \\
\text { accumula- } \\
\text { tion of } \\
\text { ice } \\
\left(\mathrm{cm} \mathrm{a}^{-1}\right)\end{array}$ & $\begin{array}{l}\text { No. of } \\
\text { records } \\
\text { compared }\end{array}$ & $\begin{array}{l}\text { No. of } \\
\text { mutual } \\
\text { d years }\end{array}$ & $\begin{array}{l}\text { Distance } \\
\text { between } \\
\text { cores } \\
\quad(m)\end{array}$ \\
\hline Dye 3 & $65^{\circ} 11^{\prime}$ & $43^{\circ} 50^{\prime}$ & 2480 & -20.3 & 57 & 3 & $32-100=$ & $500-5000$ \\
\hline Dye 2 & $66^{\circ} 29^{\prime}$ & $46^{\circ} 20^{\prime}$ & 2100 & -16.5 & 38 & 3 & $31-69$ & $2000-$ \\
\hline Milcent & $70^{\circ} 18^{\prime}$ & $44^{\circ} 33^{\prime}$ & 2450 & -22.8 & 52 & 3 & $17-21$ & $\begin{array}{c}3000 \\
1000- \\
2000\end{array}$ \\
\hline Crête & $71^{\circ} 07^{\prime}$ & $37^{\circ} 19^{\prime}$ & 3170 & -30.4 & 28 & 4 & $29-90$ & $2-100^{2000}$ \\
\hline North Central & $74^{\circ} 37^{\prime}$ & $39^{\circ} 36^{\prime}$ & 2940 & -31.0 & 15 & 3 & $45-135$ & 10 \\
\hline Camp Century & $77^{\circ} 11^{\prime}$ & $61^{\circ} 09^{\prime}$ & 1885 & -24.0 & 39 & 2 & 110 & 10000 \\
\hline Devon Island & $75^{\circ} 20^{\prime}$ & $82^{\circ} 30^{\prime}$ & 1830 & -23.0 & 24 & i & $\begin{array}{l}>10^{5} \\
(415 \\
\text { annual } \\
\text { averages) }\end{array}$ & 27 \\
\hline
\end{tabular}

The analysis of variance will provide estimates of the signal-to-noise variance ratio $F$ (Reeh and others 1977). As shown in Reeh and Fisher (1983), F may also be estimated by the expression

$$
F=r_{x y} /\left(1-r_{x y}\right)
$$

where $r_{x y}$ is the cross-correlation coefficient between the time series involved. If more than two time series are considered $(m>2), r_{x y}$ is estimated as the average value of the $\mathrm{m}(\mathrm{m}-1) / 2$ possible estimates of $\mathrm{r}_{\mathrm{xy}}$ obtained by combining the time series two by two.

A diversion is necessary here to avoid possible confusion in the method used to calculate noise and signal variance. In this paper only series of the same type are correlated. Consider, for example, two time series (say two accumulation series from neighbouring cores) $X(t)$ and $Y(t)$. We assume that both series contain the same common signal $S(t)$ plus random noise $e_{x}(t)$ and $\mathrm{e}_{\mathrm{y}}(\mathrm{t}) ; \mathrm{X}(\mathrm{t})=\mathrm{S}(\mathrm{t})+\mathrm{e}_{\mathrm{X}}(\mathrm{t})$ and $\mathrm{Y}(\mathrm{t})=\mathrm{S}(\mathrm{t})+\mathrm{e}_{\mathrm{y}}(\mathrm{t})$; also $\operatorname{Var}\left(\mathrm{e}_{\mathrm{X}}\right)=$ $\operatorname{Var}\left(\mathrm{e}_{\mathrm{y}}\right)$.

If the correlation coefficient between series $X$ and $\mathrm{Y}$ is $\mathrm{r}_{\mathrm{Xy}}$ then the total variance can be separated into signal and noise parts (Reeh and Fisher 1983) by

$$
\begin{aligned}
& \operatorname{Var}(\mathrm{S})={ }^{r} x y \operatorname{Var}(\mathrm{X}) \quad \text { for the signal } \\
& \text { and } \operatorname{Var}\left(e_{x}\right)=\left(1-r_{x y}\right) \operatorname{Var}(X) \text { for the noise }
\end{aligned}
$$

This division of signal and noise variance is the one appropriate to this work.

If, on the other hand, one correlates $X(t)$ with the pure signal series $S(t)$ then the variances of signal and noise are (Brooks and Carruthers 1953)

$$
\operatorname{Var}(S)=r_{x S}^{2} \operatorname{Var}(X) \text { for the signal }
$$

and $\operatorname{Var}\left(e_{\mathrm{X}}\right)=\left(1-\mathrm{r}_{\mathrm{XS}}^{2}\right) \operatorname{Var}(\mathrm{X})$ for the noise.

We do not ever have the pure signal available so this case is not used here.

In order to analyze the spectral distribution of the noise variance, estimates of noise series are needed. Such estimates are obtained by first estimating the signal as the average of the $\mathrm{m}$ available time series, if necessary af ter subtracting the series average from each individual series. Then each noise series is analyzed by standard
Fourier spectral methods to provide the autocorrelation function and the spectral density

distribution. The final estimates are obtained by averaging the $\mathrm{m}$ results.

The above-mentioned signal-noise separation procedure presupposes precisely aligned time series. As discussed in section 2, this holds for the GISP records, which are dated year-by-year. For the Devon Island records, which cannot be absolutely dated, a segment-by-segment matching procedure is followed to align equivalent segments (Paterson and others 1977).

The results of the noise analysis are summarized in Table II. The values listed are average values for each site. If more than two series of $\lambda$ or $\delta$ were available at the same site, allowing more than one estimate of the noise parameters, tests for homogeneity were made ( $F$ tests or Bartlett tests for variances and Yates tests for correlation coefficients). In all cases, except those involving $\delta$ records for upper firn, the tests indicate homogeneous series. The reason why upper firn $\delta$ records show significant deviations from other $\delta$ records is probably because the process of diffusive smoothing has not yet come to an end for these records. Consequently, the records have not been considered in the estimation of the noise parameters.

In this section we will limit our discussion of Table II to the relative noise parameter $\sigma_{N}(\lambda) / \bar{\lambda}$, where $\sigma_{N}(\lambda)$ is the noise part of the standard deviation of the $\lambda$ series and $\bar{\lambda}$ is the temporal average.

A Bartlett test indicates homogeneity of the relative noise variances $\sigma_{N}^{2}(\lambda) / \bar{\lambda}^{2}$ (chi-square value equal to 6.3 with 5 degrees of freedom, which is not at all significant), the average value being 0.017 . This means that, within the statistical uncertainty, $\sigma_{N}(\lambda) / \bar{\lambda}$ is constant and equal to 0.13 for all the sites considered. Since $\sigma_{N}(\lambda)$ is a measure of the snow surface roughness after a storm (to be more specific, after a winter storm), this result indicates that the average height $\mathrm{H}$ of the sastrugi varies from site to site on the ice sheet in proportion to the local rate of accumulation. If the sastrugi are assumed to have a sine curve shape, the $\sigma_{N}(\lambda) / \bar{\lambda}$ value of 0.13 found above suggests a relationship between $H$ and $\bar{\lambda}$ of the form $H=0.26 \bar{\lambda}$, where $\bar{\lambda}$ is accumulation in snow (density $\sim 350 \mathrm{~kg} \mathrm{~m}^{-3}$ ). With $\bar{\lambda}=1.6$ $\mathrm{m}$ (Dye 3), we get $\mathrm{H}=0.4 \mathrm{~m}$, which is of the right order of magnitude ( $\mathrm{S} \mathrm{J}$ Johnsen personal communication). Of course sastrugi do not have a sine curve shape but are distributed in some random pattern so the above estimate of $\mathrm{H}$ would tend to be a maximum value. 
TABLE II. NOISE PARAMETERS AS DEDUCED FROM OBSERVATIONS

\begin{tabular}{|c|c|c|c|c|c|c|c|c|c|c|c|c|c|c|c|c|c|c|c|c|}
\hline \multirow[t]{3}{*}{ Site } & $\begin{array}{l}\text { Mean } \\
\text { annual } \\
\text { accumu- } \\
\text { lation }\end{array}$ & \multicolumn{4}{|c|}{ Relative variance of $\lambda$ noise } & \multicolumn{3}{|c|}{$\begin{array}{l}\text { Lag-one serial correlation } \\
\text { coefficient of } \lambda \text { noise } \\
\text { series }\end{array}$} & \multicolumn{4}{|c|}{ Variance of $\delta$ noise } & \multicolumn{4}{|c|}{$\begin{array}{l}\text { Lag-one serial correla- } \\
\text { tion coefficient of } \delta \\
\text { noise series }\end{array}$} & \multicolumn{2}{|c|}{$\begin{array}{l}\text { Signal-to-noise } \\
\text { variance ratio } \\
\text { of } \lambda \text { series }\end{array}$} & \multicolumn{2}{|c|}{$\begin{array}{l}\text { Signal-to-noise } \\
\text { variance ratio } \\
\text { of } \delta \text { series }\end{array}$} \\
\hline & & \multicolumn{4}{|c|}{$\left(\sigma_{N}^{2}(\lambda) / \bar{\lambda}^{2}\right) 10^{2}$} & \multicolumn{3}{|c|}{$r_{1}(\lambda)$} & \multicolumn{4}{|l|}{$\sigma_{N}^{2}(\delta)$} & \multicolumn{4}{|c|}{$r_{1}(6)$} & \multicolumn{2}{|c|}{$F_{\lambda}$} & \multicolumn{2}{|l|}{$\mathrm{F}_{\delta}$} \\
\hline & $\begin{array}{l}\text { (cm } \\
\text { of } \\
\text { ice })\end{array}$ & Mean & $\begin{array}{l}\text { Degrees } \\
\text { of } \\
\text { freedom }\end{array}$ & $\begin{array}{r}95 \\
\text { conf } \\
\text { lin }\end{array}$ & $\begin{array}{l}\% \\
\text { dence } \\
\text { its }\end{array}$ & Mean 1 & $\begin{array}{l}\text { Degrees } \\
\text { of } \\
\text { freedom }\end{array}$ & $\begin{array}{l}95 \% \\
\text { confidence } \\
\text { limits }\end{array}$ & Mean I & $\begin{array}{l}\text { Degrees } \\
\text { of } \\
\text { freedom }\end{array}$ & $\begin{array}{r}95 \\
\text { conf } \\
\operatorname{lin}\end{array}$ & $\begin{array}{l}5 \% \\
\text { idence } \\
\text { mits }\end{array}$ & $\begin{array}{r}\text { Mean I } \\
f\end{array}$ & $\begin{array}{l}\text { Degrees } \\
\text { of } \\
\text { freedom }\end{array}$ & $\begin{array}{l}95 \% \\
\text { confide } \\
\text { limit }\end{array}$ & $\begin{array}{l}\% \\
\text { dence } \\
\text { its }\end{array}$ & Ratio & $\begin{array}{l}\text { Approx } \\
\text { standard } \\
\text { deviation }\end{array}$ & Ratio & $\begin{array}{l}\text { Approx } \\
\text { standard } \\
\text { deviation }\end{array}$ \\
\hline Dye 3 & 57 & 1.85 & 139 & 1.48 & 2.38 & -0.47 & 137 & $-0.59-0.32$ & 0.28 & 99 & 0.22 & 0.38 & 0.07 & 97 & $-0.13 c$ & 0.27 & 3.2 & 0.6 & 2.4 & 0.5 \\
\hline Dye 2 & 38 & 1.59 & 94 & 1.22 & 2.15 & -0.27 & 90 & $-0.44-0.07$ & 0.35 & 94 & 0.27 & 0.47 & 0.00 & 90 & -0.20 & 0.21 & 4.6 & 1.2 & 2.3 & 0.5 \\
\hline Milcent & 52 & 1.69 & 30 & 1.08 & 3.02 & -0.44 & 26 & $-0.69-0.09$ & 0.37 & 30 & 0.24 & 0.66 & -0.01 & 26 & $-0.38 c$ & 0.36 & 1.1 & 0.5 & 1.1 & 0.5 \\
\hline Crete & 29 & 1.60 & 145 & 1.28 & 2.04 & -0.49 & 139 & $-0.60-0.35$ & 0.49 & 145 & 0.39 & 0.62 & 0.24 & 139 & 0.08 & 0.39 & 1.4 & 0.3 & 1.4 & 0.3 \\
\hline $\begin{array}{l}\text { North } \\
\text { Central }\end{array}$ & 15 & 2.09 & 88 & 1.59 & 2.88 & -0.31 & 82 & $-0.49-0.11$ & 0.52 & 50 & 0.36 & 0.80 & 0.37 & 48 & $0.11 c$ & 0.58 & 1.1 & 0.3 & 2.7 & 0.8 \\
\hline $\begin{array}{l}\text { Camp } \\
\text { Century }\end{array}$ & 39 & 1.42 & 134 & 1.13 & 1.83 & -0.35 & 132 & $-0.49-0.19$ & 0.54 & 110 & 0.42 & 0.72 & 0.26 & 108 & 0.08 & 0.43 & 3.1 & 0.5 & 2.0 & 0.2 \\
\hline $\begin{array}{l}\text { Devon } \\
\text { Island }\end{array}$ & 24 & & & & & & & & 0.55 & 440 & 0.48 & 0.64 & 0.38 & 440 & 0.30 & 0.46 & & & 1.3 & 0.1 \\
\hline
\end{tabular}




\section{NOISE MODEL FOR ANNUAL LAYER THICKNESS RECORDS \\ 4.1. Noise due to unequal snow deposition}

The basic idea behind the noise model for annual layer thickness records is illustrated in Figure 1 which shows a vertical section from a nearly flat accumulation surface downwards into the snow pack. The undulating lines represent former snow surfaces. Along any vertical through a point $\mathrm{P}$ on the present surface, the distance 1 between any two consecutive surfaces represents the amount of snow deposited at $\mathrm{P}$ in a single storm $\mathrm{i}$ of

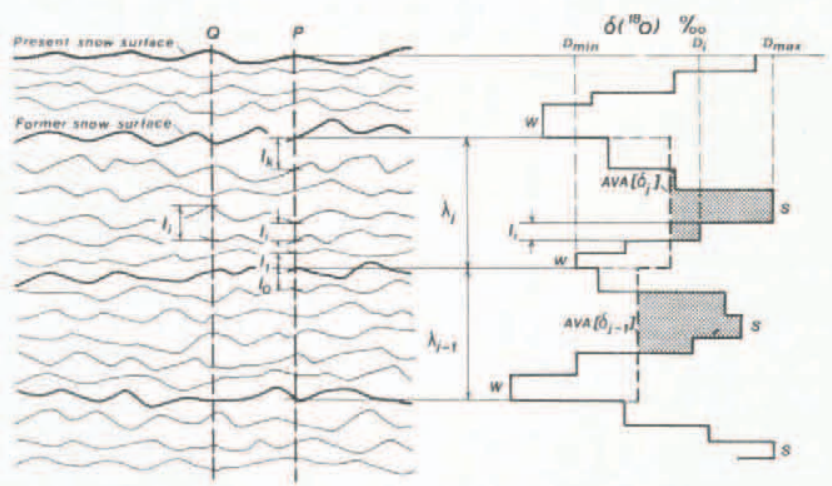

Fig.1. Vertical section from present snow surface downwards into the snowpack (schematic). For definition of symbols see text; $s$ and $w$ indicate summer and winter layers respectively.

which there are $k$ each year. Obviously the value of $I_{i}$ would be different, if measured along a vertical through another point $Q$ on the surface (Fig.1). Denoting the areal average of $l_{i}$ by $\mathrm{AVA}\left(\mathrm{l}_{i}\right\}$, we may therefore write

$$
\mathrm{I}_{\mathrm{i}}=\operatorname{AVA}\left(1_{\mathrm{i}}\right)+\mathrm{e}_{\mathrm{i}}
$$

where $e_{i}$, which is the deviation of $l_{j}$ from its areal average, represents noise. By definition, we have $A V A\left(e_{i}\right)=0$. Annual accumulation at $P$ is

$$
\lambda=\sum_{i=1}^{k} i_{i} .
$$

We assume that the temporal noise variance of $e$ denoted $\sigma_{\mathrm{e}}^{2}$ for a given site or core is equal to the areal variance of $e_{i}$ for a given storm $i$ from a set of neighbouring sites, i.e. we assume that $\sigma_{\mathrm{e}}^{2}=\mathrm{AVA}\left\{\mathrm{e}_{\mathrm{f}}^{2}\right\}$. Also we assume that the noise variance, temporal and areal, is constant with time. However, changing climatic conditions may introduce long-term oscillations of the surface roughness just as seasonal variations are likely to occur.

The noise contribution $e_{i}$ in a given storm layer $l_{i}$ is the difference of the residuals $\epsilon_{i}$ from the mean upper and lower surface of the layer

$$
e_{i}=\epsilon_{i}-\epsilon_{i-1} \text {. }
$$

Thus, in order to define the exact statistical nature of $e_{i}$, one needs a detailed knowledge of surface sastrugi $\epsilon_{\mathrm{i}}$. Since measurements of $\epsilon_{\mathrm{i}}$ are not available for the various sites, we chose a simple form for $\epsilon$. We assume $\epsilon_{i}$ at a given site has a stationary Gaussian distribution with expected value $E\left(\epsilon_{i}\right\}=0$.

Furthermore we require

$$
E\left\{\epsilon_{i} \epsilon_{i-m}\right\}=\left\{\begin{array}{l}
\sigma_{\epsilon}^{2}, \text { for } m=0 \\
0, \text { for } m>0 \\
i, m=0,1,2 \ldots k \text { storms }
\end{array}\right.
$$

The theoretical variance and autocorrelation function of the annual average noise time series become finally (Reeh and Fisher 1983)

$$
\sigma_{\mathrm{N}}^{2}(\lambda)=\sigma_{\mathrm{e}}{ }^{2},=2 \sigma_{\mathrm{e}}^{2}
$$

and

$$
\rho_{t}(\lambda)=\left\{\begin{array}{cl}
1, & t=0 \\
-1 / 2, & t=1 \\
0 & t>1,
\end{array}\right.
$$

where $t$ represents the time lag in years. The corresponding spectral density function may be written

$$
p(f)=2 \sigma_{e}{ }^{2}(1-\cos 2 \pi f), \text { for } 0>f<\frac{1}{2}
$$

where $f=\left[\frac{\Delta t}{\text { period }}\right](\Delta t$ being the sample inter-

val, which in this case is one year) and denotes dimensionless frequency.

Figure 2(a) shows a plot of the spectrum of the noise model (thick curve). It appears that most of the spectral density or power is in the high frequency end of the spectrum. By analogy to light, such a spectrum could be termed "blue". Similarly we shall regard the noise in annual layer thickness records as blue noise by analogy with the well-known concepts of white noise characterized by a uniform spectral density function and red noise characterized by concentration of the power in the low frequency end of the spectrum. Also shown in Figure 2(a) are estimated $\lambda$ noise spectra (thin curves) from Dye 3 and Crête, Greenland. All estimated spectra show typically blue appearances.
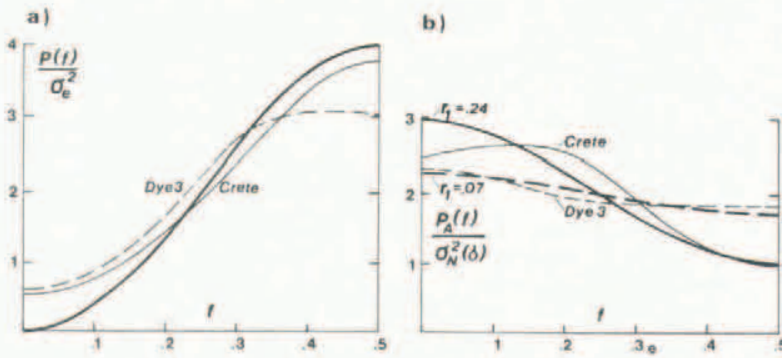

Fig.2(a). Power spectra of noise model for annual layer thickness series: relative power $P(f) / \sigma_{\mathrm{e}}^{2}$ as a function of dimensionless frequency $f=\Delta t /$ period $\left(\begin{array}{lll}\Delta t=1 & a\end{array}\right)$. Thick curve: theoretical spectrum. Thin curves: "observed" $\lambda$ noise spectra for Crête and Dye 3 .

(b). Power spectra of noise model for annual $\delta$ values. Relative power $\mathrm{P}_{\mathrm{A}}(\mathrm{f}) / \sigma_{\mathrm{N}}^{2}(\mathrm{\delta})$ as a function of dimensionless frequency $\mathrm{f}=\Delta \mathrm{t} / \mathrm{period}(\Delta \mathrm{t}=1$ a). Thick curves: theoretical spectra. Thin curves: "observed" $\delta$ noise spectra for Crête and Dye 3.

Examination of Table II shows that the actual estimates of the first (lag-one) autocorrelation $r_{1}(\lambda)$ are not significantly different from that predicted except for Dye 2 and North Central, A characteristic of both locations is that the $\delta$ seasonals are not very distinct, though for different reasons. At Dye 2 the $\delta$ seasonals are disturbed due to refreezing in the firn of large amounts of percolating meltwater. In the case of North Central the $\delta$ seasonals are gradually obliterated due to rapid diffusion in the firn and have in practice disappeared $20 \mathrm{~m}$ below the snow surface corresponding to an age of about 50 a. Both are poor sites for extracting good $\lambda$ series from $\delta\left({ }^{18} \mathrm{O}\right)$ cycles.

The difficulty in interpreting the $\delta$ seasonals, and the consequent reduction of the accuracy in separating the individual years, will introduce an additional $\lambda$ noise term which is less blue than the noise term discussed in this section and which consequently will tend to whiten the noise.

For stations such as Crête, which has virtually no melt and well-defined $\delta$ years, there is a good agreement 
between the model and "measured" values of the autocorrelation function for all lags.

Of some interest is the question of how the noise variance of the mean value of the accumulation of several years changes when the number of years increases. In the case of white noise in annual series with variance $\sigma^{2}$ it is well-known that the noise variance of the $M$ a means will decrease as $\sigma^{2} / M$. In the case of blue noise the variance will decrease even more rapidly with increasing $M$, the noise variance of the $M$ a means being $\sigma^{2} / \mathrm{M}^{2}$, (Reeh and Fisher 1983). This result is not surprising in terms of accumulation rates on ice caps. If a given spot receives more than the average annual snow accumulation one year, then it is likely to receive less during the next year. One of the few things known for certain about the accumulation areas of large ice caps is that the surface looks the same from year to year.

\subsection{Noise due to errors of separation between} consecutive layers

In the $\delta\left({ }^{18} \mathrm{O}\right)$ dating technique the points of separation between annual layers are in most cases defined at the pronounced $\delta$ minima of the record, which reflect the culmination of the winter cold.

One source of error is related to the sampling frequency used when cutting the core for $\delta\left({ }^{18} \mathrm{O}\right)$ measurements. The sampling frequency for the cores used in this study ranges from 8 to 16 samples per calculated year and, thus, the position of the $\delta$ minimum is defined within one sample length only.

Another source of error is due to the mass exchange by diffusion, which occurs mainly in the porous snow and firn of the upper layers (Johnsen 1977). This process shifts the original position of the $\delta$ minima. Minima with small (large) separations approach (retreat from) one another.

A characteristic of both kinds of separation error is that if the thickness of one layer is underestimated, then the thickness of the succeeding layer will most likely be overestimated. Thus, the noise due to separation errors resembles that of the blue accumulation noise. If, however, the $\delta$ seasonals show large deviations from the ideal regular sine curve shape, e.g. very pronounced in the case of the $\delta$ records from Dye 2 and North Central, only separation points between, say, every third or fifth year may be well-defined. In such cases the intervening points of separation are chosen more or less by chance and a white noise component is introduced.

\section{NOISE MODEL FOR $\delta\left({ }^{18} \mathrm{O}\right)$ TIME SERIES}

\subsection{Theoretical noise model}

The mean $\delta$ value of the snow at a particular time of year is taken as a constant over area and is only dependent on the time of year. It is denoted by $\mathrm{D}_{\mathrm{i}}$ and

$$
\mathrm{D}_{\mathrm{i}}=\delta^{*}+\mathrm{A} \Delta_{\mathrm{i}}
$$

where for one year $\delta^{*}$ is the true temporal mean value unweighted by accumulation, $A$ is the amplitude of the $\delta$ cycle and $\Delta_{\mathrm{i}}$ is the normalized deviation of $\mathrm{D}_{\mathrm{i}}$ from $\delta^{*}$ (see Fig.1). Since $D_{i}$ is associated with the thickness of the snow layer $l_{i}$, we have the areal average annual $\delta$ as the accumulation weighted mean

$$
\operatorname{AVA}(\delta)=\sum_{i=1}^{k} \frac{\operatorname{AVA}\left(1_{i}\right)}{\operatorname{AVA}(\lambda)} \quad D_{i}
$$

Similarly, the annual $\delta$ value measured from a single site or core is

$$
\delta=\underset{i=1}{\sum} \frac{1_{i}}{\lambda} D_{i} .
$$

The development of the $\delta$ noise theory follows much the same line as for the accumulation series. However, unlike accumulation stratigraphy, $\delta\left({ }^{18} \mathrm{O}\right)$ profiles, signal and noise are subject to vigorous smoothing by diffusion. Johnsen (1977) has provided a theory of diffusion of $\delta\left({ }^{18} \mathrm{O}\right)$ in the firn. He shows that diffusion is by vertical mixing of water vapour in the porous upper 15 to $20 \mathrm{~m}$ of firn, or, more strictly, in the layer down to the depth at which firn density reaches a value of $0.55 \mathrm{~g} \mathrm{~cm}^{-3}$ and air spaces between crystals lose contact with each other, preventing further mixing. The ratio $R$ between the final (after diffusion) amplitude $A_{1}$ and the initial amplitude $A$ of a $\delta$ cycle of wavelength $\lambda$ is given as

$$
R=A_{1} / A=\exp \left(-2 \pi^{2} L_{f}^{2} / \lambda^{2}\right),
$$

where the diffusion length $L_{f}$ for water vapour (and species transferred with it) is 7 to $8 \mathrm{~cm}$ of ice.

Equation (5.2) shows that diffusion reduces the amplitude, and thereby the variance, of any given $\delta$ cycle, and, furthermore, that the reduction is greater for the higher frequencies. Hence the overall effect of diffusion is to reduce the total variance and to transform the $\delta$ series spectrum towards redness by reducing the high frequency power.

The theoretical spectral distribution, autocovariance and autocorrelation functions for annually-averaged $\delta$ noise series are developed in Reeh and Fisher (1983). The noise model is entirely determined by its autocovariance function or equivalently by its variance $\sigma_{N}^{2}(\delta)=c_{0}(\delta)$ and autocorrelation function

$$
\rho_{t}(\delta)=c_{t}(\delta) / c_{0}(\delta), \quad t=1,2, \ldots
$$

The autocovariance function is

$$
\begin{aligned}
& C_{t}(\delta)=\frac{2 \sigma_{d}^{2}}{k} \int_{0}^{k / 2}\left[1+2 \rho_{1}(d) \cos \left(\frac{2 \pi f}{k}\right)\right] \\
& {\left[\frac{\sin \pi f}{\sin (\pi f / k)}\right]^{2} \exp \left[-4 \pi^{2}\left(L_{f} f / \lambda\right)^{2}\right] \cos (2 \pi f t) d f}
\end{aligned}
$$

$\mathrm{t}=1,2$

where

$$
\sigma_{\mathrm{d}}^{2}=\left(\frac{\mathrm{A}}{\lambda}\right]^{2} \frac{\sigma_{\mathrm{e}}^{2}}{\mathrm{k}}{\underset{\mathrm{i}=1}{\mathrm{k}} \Delta_{\mathrm{i}}^{2}}^{2}
$$

and

$$
\rho_{1}(\mathrm{~d})=-\frac{\sum_{\mathrm{i}=1}^{\mathrm{k}} \Delta_{\mathrm{i}} \Delta_{\mathrm{i}-1}}{2 \sum_{\mathrm{i}=1}^{\mathrm{k}} \Delta_{\mathrm{i}}^{2}}
$$

It appears from Equation (5.3) that the autocovariance function depends on several parameters, viz. $\mathrm{k}, \mathrm{L}_{\mathrm{f}} / \bar{\lambda}, \sigma_{\mathrm{d}}^{2}$ and $\rho_{1}(\mathrm{~d})$, of which $\sigma_{\mathrm{d}}{ }^{2}$ and $\rho_{1}(\mathrm{~d})$ in turn depend on $A$, $\sigma_{\mathrm{e}} / \bar{\lambda}, \mathrm{k}$,

$$
\sum_{i=1}^{k} \Delta^{2} \text { and } \sum_{i=1}^{k} \Delta_{i} \Delta_{i-1} \text { (see Equations (5.4) and (5.5)). }
$$

\footnotetext{
5.2. Parameters influencing the $\delta$-noise model

The parameters influencing the $\delta$-noise model are of a different nature, some being related to snow
} 
deposition ( $\left(k, \bar{\lambda}, \sigma_{\mathrm{e}}^{2}\right.$ ), some to the annual $\delta$ cycle (A, $\left.\Sigma \Delta^{2}{ }_{\mathrm{i}}, \Sigma \Delta_{\mathrm{i}} \Delta_{\mathrm{i}-1}\right)$ and some to the physical properties of the firn $\left(L_{f}\right)$.

(i) Parameters related to snow deposition

According to $\mathrm{C}$ U Hammer (personal communication) the number of distinguishable layers $k$ in an annual accumulation, as determined by electric conductivity measurements of Dye 3 and Crête ice cores, is of the order of magnitude of 20 to 25 . The temporal mean value of the annual layer thickness $\lambda$ has been determined with great accuracy for the various locations (Table II). The relative areal variability $\sigma_{e} / \bar{\lambda}$ was found to have a constant value of 0.13 for all the ice-cap sites considered.

(ii) Parameters related to the annual cycle

The amplitude $A$ of the annual $\delta$ cycle can be estimated from measured $\delta$ profiles. However, due to the rapid diffusive smoothing of high frequency oscillations in the upper firn, only cycles of age less than 1 or 2 years relative to the surface can be trusted to yield A.

Figure 3 shows A from various Greenland sites and for the Devon Island ice cap plotted against latitude (upper line). The A value for a given latitude is obtained by averaging $A$ for the uppermost year for

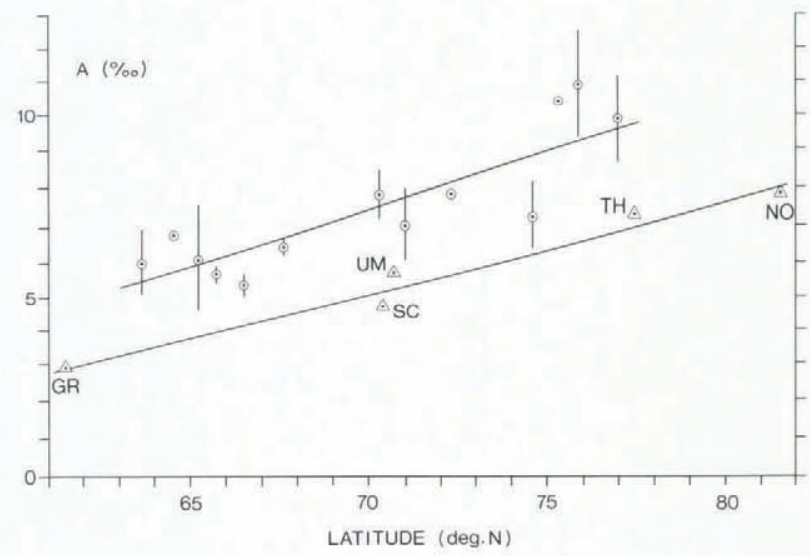

Fig.3. Seasonal $\delta$ amplitude A for the uppermost layer of snow on ice-cap sites versus latitude, and $A$ for coastal stations, lower points. Ice-cap stations within $1 / 2$ degree of latitude are averaged together. The lines are least squares linear fits. GR: Grønnedal, TH: Thule, SC: Scoresbysund, NO: Nord, UM: Umanak.

sites within half a degree of the latitude. Since 43 different $\delta$ profiles taken at different times have been used to obtain the data points represented, some of the errors inherent in using only the uppermost years have been reduced. The least squares linear fit to the data gives

$$
A=7.3+0.31(\text { lat }-69.5)
$$

where the slope determined has a standard error of \pm 0.06 .

As a check on this slope the measured $A$ values for precipitation at five coastal Greenland stations over six years have also been plotted in Figure 3. (IAEA $1969,1970,1971,1973,1975,1979$, Dansgaard 1964). The slope of the A latitude relationship for coastal stations is almost the same as for the ice-cap sites, namely $0.25 \pm 0.03$. That the coastal amplitudes are systematically lower is not surprising considering the moderating effect of the ocean.

It should be mentioned that the latitude amplitude relationship given by Equation (5.6) breaks down for latitudes greater than $80^{\circ} \mathrm{N}$. Two high-latitude profiles examined Agassiz Ice Cap $\left(80^{\circ} 40^{\prime} \mathrm{N}\right)$ on Ellesmere Island and Hans Tausen Ice Cap $\left(81^{\circ} 30^{\prime} \mathrm{N}\right)$ in north Greenland) have A about half that expected from Equation (5.6). This could be a "real" effect in the $\delta$ seasonal variations or could be due to the special characteristics of these two ice caps.
If the annual $\delta$ cycle is assumed to be shaped as a sine curve, the terms

$$
\frac{1}{\mathrm{k}} \sum_{\mathrm{i}=1}^{\mathrm{k}} \Delta_{\mathrm{i}}^{2} \text { and } \frac{1}{\mathrm{k}} \sum_{\mathrm{i}=1}^{\mathrm{k}} \Delta_{\mathrm{i}} \Delta_{\mathrm{i}-1}
$$

are functions of $k$ only. Since both terms are controlled by the variance of the sine function for $k \rightarrow \infty$, they have a common limiting value of 0.5 . Both terms are rather close to their limiting values of $k \geqslant 12$. Other shape functions than the sine curve will provide different values of the two terms. For example, sawtooth and box-shape profiles give limiting values of 0.33 and 1.0 respectively. The 0.5 value is used for these terms in the following calculations.

(iii) Parameters related to the physical properties of the firn

As already mentioned, the diffusion length $\mathrm{L}_{\mathrm{f}}$ has been taken to be $80 \mathrm{~mm}$ of ice after Johnsen (1977).

\subsection{Comparison of observed $\delta$ noise with the theoretical noise model}

For a sinusoidal $\Delta_{i}$, the first autocorrelation coefficient $\rho_{1}(\delta)$ of annual noise and the dimensionless $\delta$ noise variance $\tilde{\sigma}_{N}{ }^{2}(\delta)=\sigma_{N}{ }^{2}(\delta) \bar{\lambda}^{2} /\left(A^{2} \sigma_{N}{ }^{2}(\lambda)\right)$ depend on $\bar{\lambda}$ and $k$ only. For $\rho_{1}(\delta)$, the dependence on $k$ can even be neglected, since variations of $k$ in the interval $12<k<32$ will change the value of $\rho_{1}(\delta)$ by a few percent only. The curve in Figure $4(a)$ is based on a sine-shaped annual $\delta$ cycle and a value of $k$ equal to 20 . The shape of the curve points to diffusion as the process that largely determines the "colour" of the $\delta$-noise. The smaller the $\lambda$ value, the larger the $\rho_{1}$ value, i.e. the redder the noise.

The size of the dimensionless noise variance $\tilde{\sigma}_{N}^{2}(\delta)$ is much more dependent on $k$ than is $\rho_{1}(\delta)$, as illustrated in Figure 4(b). Also plotted in Figure 4(b) are the "measured" estimates of $\rho_{1}$ and $\sigma_{\mathrm{N}}^{2}$ i.e. $r_{1}$ and $\widetilde{\mathrm{S}}_{\mathrm{N}}$. In general, the "observed" values of $\mathrm{r}_{1}(\delta)$ are in accordance with the theoretical, and the smaller the $\lambda$ values are the larger are the $r_{1}$ values. However, for some locations (Dye 2 and Devon Island), the deviations of the "observed" values from the theoretical curve are significant at the $5 \%$ level. In the case of Dye 2 , the low observed value is probably due to a reduced diffusion caused by the frequent occurrence of ice layers in the firn formed in connection with the percolation-refreezing process. The ability of ice layers to stop diffusion in the firn effectively has been demonstrated by the observation of extraordinarily large $\delta\left({ }^{18} \mathrm{O}\right)$ gradients associated with firn samples sandwiched between ice layers.

The high $r_{1}$ value for the Devon Island ice cap indicates that the $\mathrm{L}_{\mathrm{f}}$ value used in the calculations is too small. This also seems to be the case for Camp
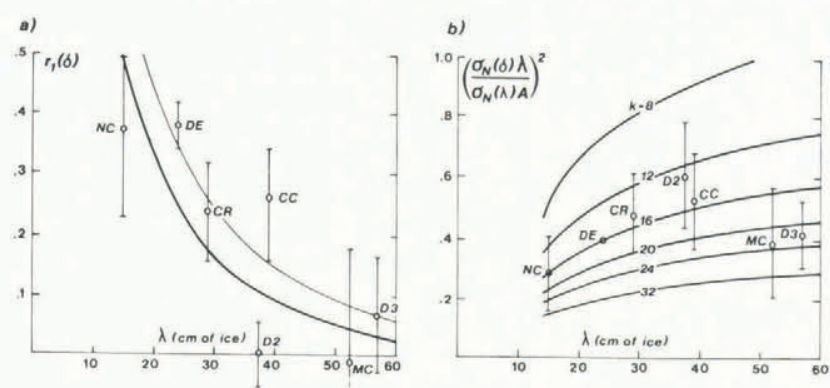

Fig.4. Comparison of observed $\delta$ noise characteristics with theoretical values (smooth curves). Error bars of observed values indicate $68 \%$ confidence limits (corresponding to one standard deviation in the case of a normal distribution).

(a) First serial correlation coefficient $r_{1}(\delta)$.

(b) Dimensionless $\delta$ noise variance $\left(\sigma_{N}(\delta) \cdot \lambda\right)^{2} /\left(\sigma_{N}(\lambda) A\right)^{2}$ as functions of annual layer thickness. DE: Devon Island, CC: Camp Century, NC: North Central, CR: Crête, MC: Milcent, D2: Dye 2, and D3: Dye 3. For definition of other symbols see text. 
Century. An increase of the diffusion length from 8 to $10 \mathrm{~cm}$ will bring the theoretical curve (thin curve in Figure 4(a)) into closer agreement with most of the observed values. The large uncertainty in the "observed" dimensionless variances $\widetilde{\mathrm{S}}_{\mathrm{N}}(\delta)$ (Fig.4(b)) precludes firm conclusions. However, the agreement between theory and observations is satisfactory. All $\tilde{\mathrm{S}}_{\mathrm{N}}(\delta)$ values are close to 0.4 . Using this value and the constant value of 0.017 found in section 3 for the relative $\lambda$ noise variance, i.e. $\sigma_{\mathrm{N}}^{2}(\lambda) / \bar{\lambda}^{2}=0.017$, gives

$$
\sigma_{N}(\delta)=0.08 \mathrm{~A} \text {. }
$$

This expression points to the amplitude of the annual $\delta$ cycle as the main factor in determining the level of the $\delta$ noise. This is confirmed by the plot in Figure 5 showing the observed $\sigma_{\mathrm{N}}(\delta)$ as a function of latitude.

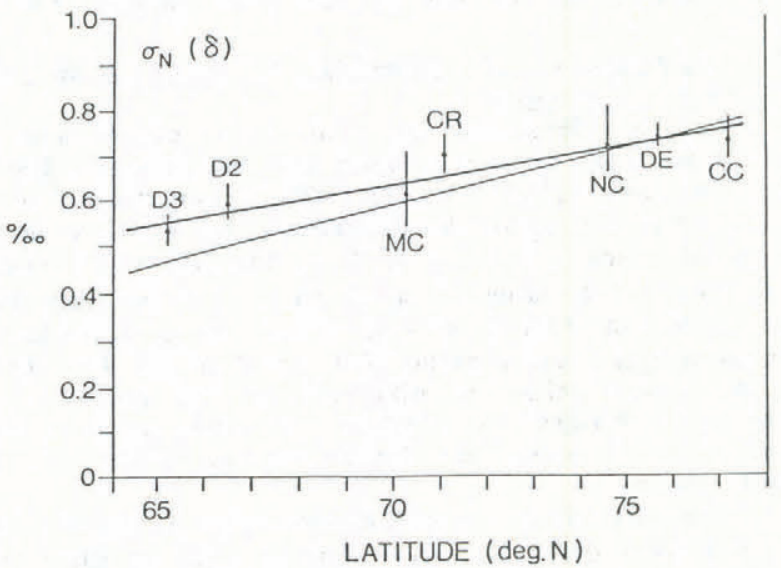

Fig.5. "Observed" $\delta$ noise standard deviations versus latitude of corresponding site of core recovery. Error bars indicate $68 \%$ confidence limits (corresponding to one standard deviation in the case of a normal distribution). Thick curve is the regression line. Thin curve is obtained from the noise model described in the text. DE: Devon Island, CC: Camp Century, NC: North Central, CR: Crête, MC: Milcent, D2: Dye 2, and D3: Dye 3.

$\sigma_{N}(\delta)$ shows a steady increase from south to north in accordance with the increase of the amplitude of the annual $\delta$ cycle (see Fig.5). The least squares linear fit to he data gives

$$
\sigma_{\mathrm{N}}(\delta)=0.66+0.017(\text { lat }-71.5)
$$

where the slope determined has a standard error of 0.003 . This regression line (thick line in Figure 5) does not deviate significantly from the line obtained by combining Equations (5.6) and (5.7) (thin line in Figure $5)$.

The theoretical power spectra for annuallyaveraged local $\delta$ noise is (Reeh and Fisher 1983)

$$
P_{A}(f)=\left\{\begin{array}{c}
\frac{k-1}{2} \\
P_{M A}(f)+\sum_{i=1} P_{M A}\left(2 \text { if } N^{ \pm} f\right) \quad k \text { odd } \\
\frac{k-2}{2} P_{M A}(f)+\sum_{i=1}\left[P_{M A}\left(2 \text { if } N^{ \pm f}\right) .\right. \\
\left.P_{M A}\left(k f_{N}-f\right)\right]
\end{array}\right.
$$

where $0 \leqslant f \leqslant f_{N}=\frac{1}{2}$.
In this equation $\mathrm{P}_{\mathrm{MA}}(\mathrm{f})$ is given by the expression

$$
\begin{aligned}
P_{M A}(f)= & \frac{2 \sigma_{d}{ }^{2}}{k}\left\{\left[1+2 \rho_{1}(d) \cos (2 \pi f / k)\right]\left[\frac{\sin \pi f}{\sin (\pi f / k)}\right]^{2} .\right. \\
& \left.\exp \left(-4 \pi^{2}\left(L_{f} / \bar{\lambda}\right)^{2} f^{2}\right)\right\} 0 \leqslant f \leqslant \frac{k}{2} .
\end{aligned}
$$

Figure 2(b) shows plots of theoretical (thick curves) and observed (thin curves) $\delta$ noise spectra for Crête and Dye 3 . The agreement is satisfactory. The power is concentrated at the low frequencies and all the spectra can be termed red.

\section{DISCUSSION AND CONCLUSIONS}

\subsection{Comments on the noise models}

The theoretical noise models presented should be considered first approximations only. Tacitly it has been assumed that the snow layers deposited by the individual storms are not mixed. In nature some mixing will always occur, the snow surface left by one storm being eroded by its successor. A comparison of the typical wave height of the winter snow-surface undulations of $0.26 \lambda$ deduced in section 3 to the average thickness of the snow layer deposited by a single storm $(0.05 \lambda$ if $\mathrm{k}=20)$ clearly shows that mixing will occur. An approximate way of taking into account the mixing would be to apply a nominal $\mathrm{k}$ less than the actual one. However, the wide confidence limits of the "observed" model parameters do not allow any firm conclusions as to the magnitude of such a reduction. It is also worth remembering that in our model seasonal variations in roughness and shape changes from year to year have been neglected. Also in our development the $\epsilon_{\mathrm{i}}$ terms, introduced in Equation (4.2), are assumed (for want of data) to be Gaussian. In fact, the $\epsilon_{\mathrm{i}}$ terms with other stationary distributions would give similar theoretical noise models. The agreement we obtain between theoretical predictions anc measurements suggests that either by chance the sastrugi $\epsilon_{\mathrm{i}}$ are Gaussian or that the noise model is not very sensitive to the exact form of the $\epsilon_{\mathrm{i}}$ distribution.

6.2. The signal-to-noise variance ratio

The signal-to-noise variance ratios $F_{\lambda}$ and $F_{6}$ of the $\lambda$ and $\delta$ series given in Table II show significantly higher values (2 to 3 ) for the southern and northern sites than for central sites (1 to 1.5). This is illustrated in Figures 6(a) and (b), where the thick line is a second degree curve fitted by least squares to the data. The second degree curve turns out to be the lowest degree polynomial, for which the sum of the squares of the deviations about the curve is no significantly larger than the expected value calculated by means of the standard deviations of the individual points.

In the case of the $\lambda$ series, the trend of the $F_{\lambda}$ curve is due to a similar trend of the relative signal variances, the relative noise variance being independent of latitude (see Table II, column 3). This points to relatively stable precipitation conditions on a year-to-year basis in central Greenland, compared to more pronounced variations in north-west and south Greenland. In south Greenland variations are probably related to the proximity of strong westerlies and consequent variable weather conditions.

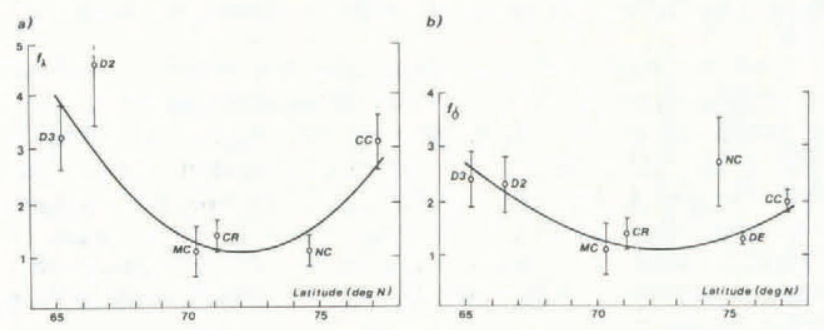

Fig.6. Signal-to-noise variance ratios $F_{\lambda}$ and $F_{\delta}$ versus latitude of the site. Error bars indicate $68 \%$ confidence limits (corresponding to one standard deviation in the case of a normal distribution). Thick curves: second degree curve fitted to the data points by least squares. DE: Devon Island, CC: Camp Century, NC: North Central, CR: Crête, MC: Milcent, D2: Dye 2, and D3: Dye 3 . 
For $\delta$ series, the explanation of the trend of the $F_{\delta}$ curve is more complicated. In this case, records from southern and central sites have equal signal variances, whereas the signal variances of northern records show increased values. Combining this pattern with the steady south to north increase of the $\delta$ noise variance (Fig.5), leads to the appearance of Figure $6(\mathrm{~b})$.

\subsection{Delta records and diffusive smoothing}

The large influence of the diffusive smoothing on the "colour" of the observed $\delta$ noise has already been pointed out. Obviously diffusion affects the signal part of a $\delta$ record in a similar manner. The redness of $\delta$ series spectra is partly a diffusion effect which is in turn sensitive to accumulation $\lambda$. Thus, before conclusions about the "colour" of climate-related variables are drawn from $\delta$ series, allowance should be made for diffusion and possible variations in diffusion related to changes in $\lambda$. It is important for interpreting spectral peaks of ice-core-derived time series to know the noise background spectrum and, for diffusing species, to realize that much of the reddening in the $\delta$ spectra could be due to difíusion effects.

\section{ACKNOWLEDGEMENTS}

The authors wish to thank Dr S J Johnsen for valuable discussions. The part of the work concerning the Greenland cores was supported by grants from the Ministry of Greenland and took place within the framework of the Greenland Ice Sheet Program. Data from Canadian ice caps was obtained with the help and financial assistance of the Polar Continental Shelf Project, EMR, Canada.

\section{REFERENCES}

Brooks C E P, Carruthers N 1953 Handbook of statistical methods in meteorology. London, Her Majesty's Stationery Office

Dansgaard W 1964 Stable isotopes in precipitation. Tellus 16(4): $436-468$

Dansgaard W, Johnsen S J, Clausen H B, Gundestrup N 1973 Stable isotope glaciology. Meddelelser om Grønland 197(2)

Fisher D A 1979 Comparison of $10^{5}$ years of oxygen isotope and insoluble impurity profiles from the Devon Island and Camp Century ice cores. Quaternary Research 11(3): 299-305

Fisher D A Unpublished A study of $\delta\left({ }^{18} \mathrm{O}\right)$ records from Devon Island ice cap, Canada and comparison of them to Camp Century $\delta$ record, Greenland. ( $\mathrm{PhD}$ thesis, University of Copenhagen, 1976)

Hammer C U 1977 Past volcanism revealed by Greenland ice sheet impurities. Nature 270(5637): 482-486

Hammer C U, Clausen H B, Dansgaard W, Gundestrup N, Johnsen S J, Reeh N 1978 Dating of Greenland ice cores by flow models, isotopes, volcanic debris, and continental dust. Journal of Glaciology 20(82): 3-26

IAEA 1969, 1970, 1971, 1973, 1975, 1979 Environment isotope data 1, 2, 3, 4, 5, 6. World survey of isotope concentration in precipitation (1953-1975). 6 Vols. Vienna, International Atomic Energy Agency (Technical Reports Series $96,117,129,147,165,192$ )

Johnsen S J 1977 Stable isotope homogenization of polar $\mathrm{f}$ irn and ice. International Association of Hydrological Sciences Publication 118 (General Assembly of Grenoble 1975 - Isotopes and Impurities in Snow and Ice): 210-219

Koerner R M 1977 Distribution of microparticles in a 299-m core through the Devon Island ice cap, Northwest Territories, Canada. International Association of Hydrological Sciences Publication 118 (General Assembly of Grenoble 1975 - Isotopes and Impurities in Snow and Ice): 371-376

Paterson W S B and 7 others 1977 An oxygen-isotope climatic record from the Devon Island ice cap, Arctic Canada. Nature 266(5602): 508-511

Reeh N, Fisher D A 1983 Noise in accumulation rate and $8\left({ }^{18} \mathrm{O}\right)$ time series as determined from comparison of adjacent Greenland and Devon Island ice cap cores. Ottawa, Polar Continental Shelf Project (Internal report)
Reeh N, Clausen H B, Gundestrup N, Johnsen S J, Stauffer B $1977 \quad \delta\left({ }^{18} \mathrm{O}\right)$ and accumulation rate distribution in the Dye 3 area, south Greenland. International Association of Hydrological Sciences Publication 118 (General Assembly of Grenoble 1975 Isotopes and Impurities in Snow and Ice): 177-181

Weatherburn C E 1968 A first course in mathematical statistics. Cambridge, Cambridge University Press 